\title{
Stress and Coping in Caregivers of Children with RASopathies: Assessment of the Impact of Caregiver Conferences
}

\author{
Athena Ganetsos ${ }^{1}$ Ellyn Farrelly ${ }^{1}$ Pilar Magoulas ${ }^{2}$ \\ ${ }^{1}$ Division of Medical Genetics, Department of Pediatrics, Stanford \\ University, Palo Alto, California, United States \\ 2 Department of Molecular and Human Genetics, Baylor College of \\ Medicine, Texas Children's Hospital, Houston, Texas, United States \\ J Pediatr Genet 2020;9:235-242.
}

David A. Stevenson ${ }^{1}$

Address for correspondence David A. Stevenson, MD, Division of Medical Genetics, Stanford University, 300 Pasteur Drive, H315, Stanford, CA 94305, United States (e-mail: dasteven@stanford.edu).

\begin{abstract}
Keywords

- Costello syndrome

- cardiofaciocutaneous syndrome

- RASopathies

The study aimed to assess baseline stress and coping mechanisms among caregivers of children with RASopathies (i.e., cardiofaciocutaneous and Costello's syndrome) and the impact of attending biennial caregiver conferences. Caregivers completed the Perceived Stress Scale, Coping Health Inventory for Parents, and demographic surveys prior to family conferences, and 1- and 6-month postconferences. Baseline stress was increased and associated with child age, parental age, and number of conferences attended. After 1 month, caregiver stress was lowered among men and caregivers attending $\geq 2$ support conferences.
\end{abstract}

\section{Introduction}

The RASopathies are a group of neurodevelopmental disorders caused by germline pathogenic variants in genes involved in the Ras-MAPK signal transduction pathway (e.g., Noonan syndrome, Costello syndrome, cardiofaciocutaneous [CFC] syndrome, neurofibromatosis type 1). Major characteristics of the RASopathies include heart defects, facial anomalies, short stature, skin abnormalities, and varying degrees of intellectual disability. ${ }^{1}$ In addition to these well-described clinical features, studies have reported increased psychopathological and autistic-like behaviors among individuals with RASopathies, particularly in CFC and Costello syndrome. ${ }^{2}$

Previous studies demonstrated an increase in stress among caregivers of individuals with neurocognitive impairment including unspecified developmental delay and autism. ${ }^{3-6}$ There have also been several studies evaluating interventions aimed to improve stress levels and coping behaviors among caregivers of children with many different neurodevelopmental disorders. ${ }^{7,8}$ However, there is limited information in caregivers of individuals with RASopathies.

received

February 14, 2020

accepted after revision

April 20, 2020

published online

May 22, 2020
Many support organizations, including CFC International and the Costello Syndrome Family Network, have organized biennial caregiver conferences for the purpose of providing education and support to caregivers of children with RASopathies. Although it is our experience that caregivers anecdotally report changes to stress levels and coping behaviors after attending these conferences, studies specifically evaluating the ability of these conferences to decrease caregiver stress and improve coping mechanisms are lacking.

Our study aimed to assess baseline stress and coping mechanisms and whether attending caregiver conferences helps reduce stress and alter coping mechanisms among caregivers of children with RASopathies, particularly CFC and Costello syndrome.

\section{Materials and Methods}

\section{Baseline Cohort}

Caregivers of individuals with CFC and Costello syndrome were recruited through CFC International and the Costello Syndrome Family Network, respectively. For inclusion, individuals had to identify as a caregiver of an individual with a molecular
Copyright @ 2020 by Georg Thieme Verlag KG, Stuttgart . New York
DOI https://doi.org/ 10.1055/s-0040-1712178. ISSN 2146-4596. 
diagnosis of CFC or Costello syndrome. Caregivers who were not planning to attend a future CFC and Costello family conference were not excluded from participating in the baseline survey but were excluded from completing follow-up surveys postconference. Enrolled participants completed the following: (1) demographic information, (2) the Perceived Stress Scale (PSS-14) questionnaire, and (3) the Coping Health Inventory for Parents (CHIP) questionnaire. Informed consent was obtained from all individual participants included in the study. This study was approved by the Institutional Review Board at Stanford University.

\section{Measures}

\section{PSS-14}

The PSS-14 includes 14 questions which ask how often the respondents perceive their lives to be stressful on a five-point scale with 0 being never, and 4 being very often. A higher score indicates a higher degree of perceived stress. ${ }^{9,10}$ For comparison, data on perceived stress in the general population were obtained from a study by Cohen and Williamson. ${ }^{10}$

\section{CHIP}

The CHIP was used to measure coping mechanisms. ${ }^{11}$ It is a 45-item instrument that measures a respondent's perception of how he or she copes with having a child with a chronic illness by choosing the degree of helpfulness of each coping item on a scale from 0 (not helpful) to 3 (extremely helpful). The instrument has three subscales: maintaining family integration, cooperation, and an optimistic definition of the situation (CHIP I), maintaining social support, self-esteem, and psychological stability (CHIP II), and understanding the medical situation through communication with other parents and consultation with medical staff (CHIP III). ${ }^{11} \mathrm{~A}$ higher score in any given subscale reflects a greater use of that particular coping pattern.

\section{Demographic Survey}

Data on each caregiver's age, ethnicity, sex, highest level of education completed, and caregiver identity (e.g., mother, father, grandparent) were collected. Additional data on the age of the individual with a RASopathy, the diagnosis, and the causative mutation were collected. Caregivers were also asked to specify how many individuals currently live in their household, how many children they have living at home under the age of 16 years, and how many disease-specific support conferences they have attended.

\section{Conferences}

Every other year, CFC International and the Costello Syndrome Family Network hold conferences to gather families impacted by CFC and Costello syndrome, as well as researchers, physicians, and other experts from around the world. These conferences aim to provide education and support to caregivers of individuals with CFC and Costello syndrome. The conferences generally include the following components: physician engagement (through individualized discussions with various specialists), presentations from leading experts in CFC and
Costello syndrome, recreational activities (e.g., magic shows and movie nights), respite outings for caregivers and siblings, and opportunities to participate in research.

An invitation to participate in the study, with a link to the baseline questionnaire, was emailed to a distribution list provided by CFC International and the Costello Syndrome Family Network prior to each family conference. Additional participants were recruited at the conferences themselves.

\section{Conference Cohort}

Individuals who attended either the CFC International or the Costello Syndrome Family Network conference after completing baseline questionnaires were included in the conference cohort. Participants in the conference cohort were given the PSS-14 and CHIP questionnaires at 1- and 6-month postconferences.

\section{Data Analysis}

Descriptive statistics were used to characterize the sample of respondents. Linear regression analysis was used to determine the association between parental stress and coping (as dependent variables) and independent variables including age of the caregiver, age of the child with the RASopathy, age of diagnosis, number of other young children living at home, and number of support conferences attended. Paired samples $t$-tests were used to compare the mean scores of the PSS-14, CHIP I, CHIP II, and CHIP III in respondents that answered the questionnaires both pre- and postconferences. Paired sample $t$-tests were also used to compare the mean scores of the four measures (PSS-14, CHIP I, CHIP II, and CHIP III) between sexes, between caregivers of individuals with CFC syndrome and caregivers of individuals with Costello syndrome, and between "new" conference attendees (0-1 conferences attended) and "seasoned" conference attendees ( $\geq 2$ conferences attended). The analyses were performed using SPSS version 24.0 (IBM Corp.; Armonk, New York, United States).

\section{Results}

\section{Baseline Cohort}

One hundred thirty caregivers from 104 households responded to the baseline survey. Demographic characteristics of the baseline cohort are summarized in - Table 1.

The mean PSS-14 score for the baseline cohort was 24.68 . This represents $\sim 44 \%$ of the maximum value for the PSS-14 stress score (56) and exceeds the general population PSS-14 score of $19.62 .^{10}$

The mean (standard deviation [SD]) CHIP I ("maintaining family integration"), CHIP II ("maintaining social support"), and CHIP III ("understanding the medical situation") scores in the baseline study cohort were 35.38 (9.29), 27.75 (9.65), and 14.97 (4.95), respectively. These scores represent 62.1, 51.4 , and $62.4 \%$ of the maximum CHIP subscale scores (57, 54 , and 24). A higher maximum percentage score indicates a higher use of the coping behavior described in each subscale.

Linear regression analysis on the baseline cohort showed a statistically significant association between decreased PSS-14 scores and older age of child with a RASopathy $(b=-0.289$, 
Table 1 Demographic data

\begin{tabular}{|c|c|c|c|}
\hline & Baseline & 1-mo cohort & 6-mo cohort \\
\hline Caregivers & 130 & 56 & 45 \\
\hline \multirow[t]{2}{*}{ Sex } & Males: 38 (29.2\%) & Males: 8 (14.3\%) & Males: 5 (11.1\%) \\
\hline & Females: 92 (70.8\%) & Females: 48 (85.7\%) & Females: 40 (88.9\%) \\
\hline Mothers & $90(69.2 \%)$ & 47 (83.9\%) & $38(84.4 \%)$ \\
\hline Fathers & $37(28.5 \%)$ & $8(14.3 \%)$ & $5(11.1 \%)$ \\
\hline Grandparents & $2(1.5 \%)$ & $0(0 \%)$ & $1(2.2 \%)$ \\
\hline Siblings & $1(0.8 \%)$ & $1(1.8 \%)$ & $1(2.2 \%)$ \\
\hline $\begin{array}{l}\text { Mean caregiver } \\
\text { age }(y)\end{array}$ & $\begin{array}{l}46.4(N=129 ; \text { range: } 27-81 ; \\
\text { SD: } 11.4)\end{array}$ & $\begin{array}{l}45.8(N=55 ; \text { range: } 27-71 \\
\text { SD: } 11.0)\end{array}$ & 45.2 (range: 30-71; SD: 11.2) \\
\hline Mothers' age (y) & $\begin{array}{l}43.8(N=89 ; \text { range: } 27-71 \\
\text { SD: } 10.4)\end{array}$ & $\begin{array}{l}44.7(N=46 ; \text { range: } 27-71 \text {; } \\
\text { SD: } 10.8)\end{array}$ & 43.8 (range: 30-71; SD: 11.2) \\
\hline Fathers' age (y) & 50.9 (range: 35-81; SD: 11.3) & $\begin{array}{l}49.5(N=8 \text {; range: } 36-67 \text {; } \\
\text { SD: } 11.7)\end{array}$ & 50.0 (range: 42-62; SD: 8.5) \\
\hline $\begin{array}{l}\text { Grandparents' } \\
\text { age (y) }\end{array}$ & 66 (range: 59-73; SD: 9.9) & $\mathrm{N} / \mathrm{A}$ & $59(N=1)$ \\
\hline Siblings' age (y) & $62(N=1)$ & $62(N=1)$ & $62(N=1)$ \\
\hline $\begin{array}{l}\text { Age of individual } \\
\text { with RASopathy (y) }\end{array}$ & 12.0 (range: 0.7-63; SD: 10.4) & 13.2 (range: 1-63; SD: 11.6) & 12.8 (range: 1-63; SD: 12.3) \\
\hline \multirow[t]{2}{*}{ Child's diagnosis } & CFC: 47 (36.2\%) & CFC: 21 (37.5\%) & CFC: 13 (28.9\%) \\
\hline & Costello: $83(63.8 \%)$ & Costello: 35 (62.5\%) & Costello: 32 (71.1\%) \\
\hline \multirow[t]{4}{*}{ Caregiver education } & High school: 25 (19.2\%) & High school: 10 (17.9\%) & High school: 8 (17.8\%) \\
\hline & $\begin{array}{l}\text { Undergraduate } \\
\text { degree: } 49(37.7 \%)\end{array}$ & $\begin{array}{l}\text { Undergraduate } \\
\text { degree: } 27 \text { (48.2\%) }\end{array}$ & $\begin{array}{l}\text { Undergraduate } \\
\text { degree: } 23 \text { (51.1\%) }\end{array}$ \\
\hline & $\begin{array}{l}\text { Graduate or professional } \\
\text { degree: } 53(40.8 \%)\end{array}$ & $\begin{array}{l}\text { Graduate or professional } \\
\text { degree: } 19(33.9 \%)\end{array}$ & $\begin{array}{l}\text { Graduate or professional } \\
\text { degree: } 14(31.1 \%)\end{array}$ \\
\hline & None of the above: 3 (2.3\%) & None of the above: $0(0 \%)$ & None of the above: $0(0 \%)$ \\
\hline \multirow[t]{3}{*}{ Ethnicity } & Hispanic or Latino: 11 (8.5\%) & Hispanic or Latino: 2 (3.6\%) & Hispanic or Latino: 3 (6.7\%) \\
\hline & $\begin{array}{l}\text { Not Hispanic or Latino: } 112 \\
(86.2 \%)\end{array}$ & Not Hispanic or Latino: 52 (92.9\%) & Not Hispanic or Latino: 41 (91.1\%) \\
\hline & Unknown/not reported: 7 (5.4\%) & Unknown/not reported: 2 (3.6\%) & Unknown/not reported: 1 (2.2\%) \\
\hline \multirow[t]{7}{*}{ Race } & $\begin{array}{l}\text { American Indian/ } \\
\text { Alaska Native: } 0(0 \%)\end{array}$ & $\begin{array}{l}\text { American Indian/ } \\
\text { Alaska Native: } 0(0 \%)\end{array}$ & $\begin{array}{l}\text { American Indian/ } \\
\text { Alaska Native: } 0(0 \%)\end{array}$ \\
\hline & Asian: 4 (3.1\%) & Asian: 2 (3.6\%) & Asian: 2 (4.4\%) \\
\hline & $\begin{array}{l}\text { Native Hawaiian or } \\
\text { Pacific Islander: } 1(0.8 \%)\end{array}$ & $\begin{array}{l}\text { Native Hawaiian or } \\
\text { Pacific Islander: } 1 \text { (1.8\%) }\end{array}$ & $\begin{array}{l}\text { Native Hawaiian or } \\
\text { Pacific Islander: } 1 \text { (2.2\%) }\end{array}$ \\
\hline & $\begin{array}{l}\text { Black or African American: } 1 \\
(0.8 \%)\end{array}$ & Black or African American: 0 (0\%) & Black or African American: 0 (0\%) \\
\hline & White: 115 (88.5\%) & White: 50 (89.3\%) & White: 41 (91.1\%) \\
\hline & More than one race: $8(6.2 \%)$ & More than one race: 3 (5.4\%) & More than one race: 1 (2.2\%) \\
\hline & Unknown/not reported: 1 (0.8\%) & Unknown/not reported: 0 (0\%) & Unknown/not reported: 0 (0\%) \\
\hline \multirow{7}{*}{$\begin{array}{l}\text { Number of children } \\
\text { living at } \\
\text { home }<16 \text { y } \\
\text { (per household) }\end{array}$} & $0=33(25.4 \%)$ & $0=13(25.5 \%)$ & $0=13(31.0 \%)$ \\
\hline & $1=29(23.3 \%)$ & $1=8(15.7 \%)$ & $1=9(21.4 \%)$ \\
\hline & $2=40(30.8 \%)$ & $2=18(35.3 \%)$ & $2=13(31.0 \%)$ \\
\hline & $3=16(12.3 \%)$ & $3=6(11.8 \%)$ & $3=5(11.9 \%)$ \\
\hline & $4=9(6.9 \%)$ & $4=4(7.8 \%)$ & $4=2(4.8 \%)$ \\
\hline & $5=3(2.3 \%)$ & $5=2(3.9 \%)$ & $5=0(0 \%)$ \\
\hline & $N=104$ households & $N=51$ households & $N=42$ households \\
\hline
\end{tabular}

(Continued) 
Table 1 (Continued)

\begin{tabular}{|l|l|l|l|}
\hline & Baseline & 1-mo cohort & 6-mo cohort \\
\hline \multirow{4}{*}{$\begin{array}{l}\text { Number of support } \begin{array}{l}\text { conferences } \\
\text { attended }\end{array} \\
\end{array}$} & $0=26(20 \%)$ & $1=7(12.5 \%)$ & $0=15(33.3 \%)$ \\
\cline { 2 - 4 } & $1=21(16.2 \%)$ & $2=12(21.4 \%)$ & $1=4(8.9 \%)$ \\
\cline { 2 - 4 } & $2=29(22.3 \%)$ & $3=6(10.7 \%)$ & $2=8(17.8)$ \\
\cline { 2 - 4 } & $3=16(12.3 \%)$ & $4=7(12.5 \%)$ & $3=5(11.1 \%)$ \\
\cline { 2 - 4 } & $4=9(6.9 \%)$ & $5=1(1.8 \%)$ & $4=4(8.9 \%)$ \\
\cline { 2 - 4 } & $5=6(4.6 \%)$ & $6=3(5.4 \%)$ & $5=0(0 \%)$ \\
\cline { 2 - 4 } & $6=3(2.3 \%)$ & $7=2(3.6 \%)$ & $6=1(2.2 \%)$ \\
\cline { 2 - 4 } & $7=3(2.3 \%)$ & $8=2(3.6 \%)$ & $7=1(2.2 \%)$ \\
\cline { 2 - 4 } & $8=5(3.9 \%)$ & $9=3(5.4 \%)$ & $8=1(2.2 \%)$ \\
\cline { 2 - 4 } & $9=6(4.6 \%)$ & $10=2(3.6 \%)$ & $9=4(8.9 \%)$ \\
\cline { 2 - 4 } & $10=5(3.9 \%)$ & $11=0(0 \%)$ & $10=2(4.4 \%)$ \\
\cline { 2 - 4 } & $11=1(0.8 \%)$ & $11=0(0 \%)$ \\
\hline
\end{tabular}

Abbreviations: CFC, cardiofaciocutaneous; N/A, not available; SD, standard deviation.

$p=0.001)$, a significant association between decreased parental PSS-14 scores and older age of the parents $(b=-0.332$, $p<0.001$ ), a significant association between increased PSS-14 scores and greater number of children living at home under the age of 16 years $(b=0.265, p=0.002)$, and a significant association between decreased PSS-14 scores and a higher number of support conferences attended $(b=-0.405, p<0.001)$. An independent samples $t$-test performed between the scores for the CFC syndrome caregivers versus the Costello syndrome caregivers revealed no statistically significant difference in the PSS-14 stress scores between the two groups $(p=0.160)$.

\section{1-Month Cohort}

Fifty-six caregivers from 51 households responded to the 1month follow-up survey. Demographic characteristics from this cohort are summarized in - Table 1 .

The mean PSS-14 score for the cohort that responded to the 1-month postconference survey was 22.84 (SD: 7.98) ( - Table 2). Like the mean PSS-14 stress score for the baseline cohort, the mean PSS-14 stress score for the 1-month followup cohort exceeded general population values. ${ }^{10}$ The mean PSS-14 stress score among those who completed both the baseline survey and the 1-month follow-up survey was lower at 1-month postconference (mean stress score was 24.64 at baseline and 22.84 at 1-month postconference). However, the difference between the means did not reach statistical significance for this cohort overall $(t=1.987, p=0.052)$, though the difference was statistically significant for men $(t=4.51, p=0.004)$ when compared with women $(t=1.54$, $p=0.129)$.

The mean CHIP I, CHIP II, and CHIP III scores among the cohort that completed both the baseline and 1-month followup surveys represented $59.1,50.2$, and $60.6 \%$ of the maximum possible scores for the CHIP subscales at baseline, and 58.8, 49.9 , and $57.8 \%$ of the maximum possible scores 1 -month postconference. Results of each of the CHIP subscales are shown in -Table 3. There was not a statistically significant
Table 2 PSS-14 scores at baseline versus 1 month

\begin{tabular}{|l|l|l|l|}
\hline & $\begin{array}{l}\text { Baseline } \\
\text { mean (SD) }\end{array}$ & $\begin{array}{l}\text { 1-mo } \\
\text { mean (SD) }\end{array}$ & $p$-Value \\
\hline $\begin{array}{l}\text { Entire cohort } \\
(N=56)\end{array}$ & $24.64(8.30)$ & $22.84(7.98)$ & 0.052 \\
\hline Women $(N=48)$ & $24.63(8.34)$ & $23.00(8.14)$ & 0.129 \\
\hline Men $(N=8)$ & $24.75(8.63)$ & $21.88(7.38)$ & 0.004 \\
\hline $\begin{array}{l}\text { Costello } \\
\text { group }(N=35)\end{array}$ & $24.26(8.02)$ & $22.17(7.87)$ & 0.032 \\
\hline $\begin{array}{l}\text { CFC group } \\
(N=21)\end{array}$ & $25.29(8.91)$ & $23.95(8.23)$ & 0.487 \\
\hline $\begin{array}{l}0-1 \text { support } \\
\text { conferences } \\
\text { attended }(N=18)\end{array}$ & $26.44(8.83)$ & $25.78(8.18)$ & 0.706 \\
\hline $\begin{array}{l}\geq 2 \text { support } \\
\text { conferences } \\
\text { attended }(N=38)\end{array}$ & $23.79(8.01)$ & $21.45(7.59)$ & 0.033 \\
\hline
\end{tabular}

Abbreviations: CFC, cardiofaciocutaneous; PSS, Perceived Stress Scale; SD, standard deviation.

difference in the use of coping mechanisms evaluated by the CHIP between baseline and 1-month postconference.

\section{6-Month Cohort}

Forty-five caregivers completed the 6-month follow-up survey. The mean PSS-14 score among caregivers who completed both the baseline survey and the 6-month follow-up survey $(N=45)$ was not statistically lower at 6 -month postconference (mean stress score was 23.98 at baseline and 23.91 postconference) (-Table 4 ). The mean PSS-14 score among caregivers who completed both the 1 - and 6-month surveys $(N=35)$ was higher at 6 months than at 1 -month postconference (22.46 at 1 -month and 23.71 at 6 -month postconferences). However, this difference was not statistically significant overall $(t=-1.023 ; p=0.313)$. 
Stress and Coping in RASopathies Ganetsos et al. 239

Table 3 CHIP values at baseline versus 1 month

\begin{tabular}{|c|c|c|c|}
\hline & $\begin{array}{l}\text { Baseline } \\
\text { mean (SD) }\end{array}$ & $\begin{array}{l}\text { 1-mo } \\
\text { mean (SD) }\end{array}$ & $p$-Value \\
\hline \multicolumn{4}{|l|}{ CHIP I } \\
\hline Entire cohort & $33.66(8.56)$ & $33.54(8.87)$ & 0.89 \\
\hline Women & $33.52(8.90)$ & 33.85 (8.79) & 0.73 \\
\hline Men & $34.50(6.50)$ & $31.63(9.69)$ & 0.15 \\
\hline Costello group & $33.23(7.90)$ & $33.49(8.14)$ & 0.79 \\
\hline CFC group & $34.38(9.71)$ & $33.62(10.18)$ & 0.66 \\
\hline $\begin{array}{l}\text { 0-1 support } \\
\text { conferences } \\
\text { attended }\end{array}$ & $34.06(10.40)$ & $33.67(10.47)$ & 0.78 \\
\hline $\begin{array}{l}\geq 2 \text { support } \\
\text { conferences } \\
\text { attended }\end{array}$ & $33.47(7.68)$ & $33.47(8.16)$ & 1.00 \\
\hline \multicolumn{4}{|l|}{ CHIP II } \\
\hline Entire cohort & $27.11(9.73)$ & $26.95(9.57)$ & 0.88 \\
\hline Women & $27.54(10.22)$ & 27.69 (1.19) & 0.88 \\
\hline Men & $24.50(5.86)$ & $22.50(15.37)$ & 0.67 \\
\hline Costello group & $26.91(9.38)$ & $27.31(9.90)$ & 0.76 \\
\hline CFC group & $27.43(10.52)$ & $26.33(9.21)$ & 0.54 \\
\hline $\begin{array}{l}\text { 0-1 support } \\
\text { conferences } \\
\text { attended }\end{array}$ & $27.61(10.20)$ & $28.00(6.91)$ & 0.83 \\
\hline $\begin{array}{l}\geq 2 \text { support } \\
\text { conferences } \\
\text { attended }\end{array}$ & $26.87(9.63)$ & $26.45(10.65)$ & 0.75 \\
\hline \multicolumn{4}{|l|}{ CHIP III } \\
\hline Entire cohort & $14.54(4.71)$ & $13.86(5.55)$ & 0.31 \\
\hline Women & $14.92(4.70)$ & $14.29(5.43)$ & 0.36 \\
\hline Men & $12.25(4.33)$ & $11.25(5.90)$ & 0.69 \\
\hline Costello group & $13.94(4.98)$ & $13.57(5.70)$ & 0.62 \\
\hline CFC group & $15.52(4.13)$ & $14.33(5.41)$ & 0.35 \\
\hline $\begin{array}{l}0-1 \text { support } \\
\text { conferences } \\
\text { attended }\end{array}$ & $15.06(4.68)$ & $15.17(5.51)$ & 0.93 \\
\hline $\begin{array}{l}\geq 2 \text { support } \\
\text { conferences } \\
\text { attended }\end{array}$ & $14.29(4.76)$ & $13.24(5.53)$ & 0.19 \\
\hline
\end{tabular}

Abbreviations: CFC, cardiofaciocutaneous; CHIP, Coping Health Inventory for Parents; SD, standard deviation.

The mean CHIP I, CHIP II, and CHIP III scores among the cohort that completed the 6-month follow-up survey represented $60.6,52.2$, and $62.6 \%$ of the maximum possible scores for the CHIP subscales at baseline, and $61.3,52.0$, and $54.0 \%$ of the maximum possible scores 6 -month postconference. Results of each of the CHIP subscales are shown in - Table 5 .

\section{Discussion}

Our data document that caregivers of individuals with CFC and Costello syndrome experience higher levels of stress as compared with the general population, suggesting that these
Table 4 PSS-14 scores at baseline versus 6 months

\begin{tabular}{|c|c|c|c|}
\hline & $\begin{array}{l}\text { Baseline } \\
\text { mean (SD) }\end{array}$ & $\begin{array}{l}\text { 6-mo } \\
\text { mean (SD) }\end{array}$ & $p$-Value \\
\hline \multicolumn{4}{|l|}{ PSS-14 } \\
\hline $\begin{array}{l}\text { Entire } \\
\text { cohort } \\
(N=45)\end{array}$ & $23.98(8.71)$ & $23.91(7.51)$ & 0.950 \\
\hline $\begin{array}{l}\text { Women } \\
(N=40)\end{array}$ & $24.45(9.01)$ & $24.78(7.32)$ & 0.775 \\
\hline Men $(N=5)$ & $20.20(4.81)$ & $17.00(5.66)$ & 0.282 \\
\hline $\begin{array}{l}\text { Costello } \\
\text { group } \\
(N=32)\end{array}$ & $24.19(8.40)$ & $23.66(7.10)$ & 0.665 \\
\hline $\begin{array}{l}\text { CFC group } \\
(N=13)\end{array}$ & $23.46(9.76)$ & $24.54(8.73)$ & 0.617 \\
\hline $\begin{array}{l}0-1 \text { support } \\
\text { conferences } \\
\text { attended } \\
(N=19)\end{array}$ & $27.05(9.70)$ & 26.05 (7.07) & 0.598 \\
\hline $\begin{array}{l}\geq 2 \text { support } \\
\text { conferences } \\
\text { attended } \\
(N=26)\end{array}$ & $21.73(7.30)$ & $22.35(7.57)$ & 0.618 \\
\hline
\end{tabular}

Abbreviations: CFC, cardiofaciocutaneous; PSS, Perceived Stress Scale; $\mathrm{SD}$, standard deviation.

individuals could benefit from interventions aimed to reduce stress and alter coping behaviors. Many factors likely contribute to the increased stress observed among caregivers of individuals with RASopathies. A recent study of parenting stress in CFC syndrome indicated that sources of stress include duties related to medical caregiving such as helping their child with medical procedures or hygiene needs, concerns regarding the long-term impact of the condition, concerns relating to managing the needs of other family members, and disruption of their own self-care needs. ${ }^{6}$

Previous studies reported an increase in psychopathology and autistic-like behaviors in individuals with RASopathies. ${ }^{2,12,13}$ Specifically, studies demonstrated that children with CFC syndrome are at high risk for attention problems, social difficulties, obsessive thoughts, and stereotyped behaviors. ${ }^{2,12}$ Caregivers' self-reported stress has been found to be significantly higher among children who engaged in more problem behaviors. ${ }^{6}$ Individuals with Costello syndrome who have a unique personality profile have been reported to be at risk for internalizing problems, such as elevated anxiety and stress. ${ }^{14-16}$ Numerous studies have found that parents of children with autism spectrum disorders experience higher levels of stress than both the general population as well as parents of children with other developmental disabilities and chronic illnesses. ${ }^{17-21}$ In addition to these well-described risk factors, our study demonstrated an association between increased parental stress and younger age of the child with the RASopathy, younger age of the caregivers, and greater number of children living at home under the age of 16 years. 
Table 5 CHIP values at baseline versus 6 months

\begin{tabular}{|c|c|c|c|}
\hline & $\begin{array}{l}\text { Baseline } \\
\text { mean (SD) }\end{array}$ & $\begin{array}{l}\text { 6-mo } \\
\text { mean (SD) }\end{array}$ & $p$-Value \\
\hline \multicolumn{4}{|l|}{ CHIP I (max = 57) } \\
\hline Entire cohort & 34.53 (8.09) & $34.93(9.53)$ & 0.68 \\
\hline Women & $34.48(8.18)$ & $34.70(9.71)$ & 0.83 \\
\hline Men & $35.00(8.16)$ & $36.80(8.67)$ & 0.29 \\
\hline Costello group & $34.97(8.47)$ & $34.56(9.10)$ & 0.72 \\
\hline CFC group & $33.46(7.26)$ & $35.85(10.87)$ & 0.22 \\
\hline $\begin{array}{l}\text { 0-1 support } \\
\text { conferences } \\
\text { attended }\end{array}$ & $34.16(10.00)$ & $34.63(9.15)$ & 0.73 \\
\hline $\begin{array}{l}\geq 2 \text { support } \\
\text { conferences } \\
\text { attended }\end{array}$ & $34.81(6.56)$ & $35.15(9.98)$ & 0.80 \\
\hline \multicolumn{4}{|l|}{ CHIP II $(\max =54)$} \\
\hline Entire cohort & $28.20(8.09)$ & $28.64(8.66)$ & 0.67 \\
\hline Women & $28.13(8.03)$ & $28.90(8.79)$ & 0.50 \\
\hline Men & $28.80(9.52)$ & $26.60(8.11)$ & 0.12 \\
\hline Costello group & $27.50(8.78)$ & $27.38(8.14)$ & 0.92 \\
\hline CFC group & $29.92(6.03)$ & $31.77(9.42)$ & 0.26 \\
\hline $\begin{array}{l}0-1 \text { support } \\
\text { conferences } \\
\text { attended }\end{array}$ & $26.11(6.82)$ & $29.00(7.02)$ & 0.07 \\
\hline $\begin{array}{l}\geq 2 \text { support } \\
\text { conferences } \\
\text { attended }\end{array}$ & $29.73(8.71)$ & $28.38(9.81)$ & 0.31 \\
\hline \multicolumn{4}{|l|}{ CHIP III $(\max =24)$} \\
\hline Entire cohort & $15.02(4.81)$ & $12.96(5.56)$ & $<0.01$ \\
\hline Women & $15.08(4.80)$ & $13.03(5.61)$ & $<0.01$ \\
\hline Men & $14.60(5.41)$ & $12.40(5.68)$ & 0.55 \\
\hline Costello group & $14.75(5.20)$ & $12.69(6.35)$ & 0.02 \\
\hline CFC group & $15.69(3.78)$ & $13.62(2.90)$ & 0.05 \\
\hline $\begin{array}{l}0-1 \text { support } \\
\text { conferences } \\
\text { attended }\end{array}$ & $15.47(4.88)$ & $13.21(5.23)$ & $<0.01$ \\
\hline $\begin{array}{l}\geq 2 \text { support } \\
\text { conferences } \\
\text { attended }\end{array}$ & $14.69(4.82)$ & $12.77(5.87)$ & 0.05 \\
\hline
\end{tabular}

Abbreviations: CFC, cardiofaciocutaneous; CHIP, Coping Health Inventory for Parents; SD, standard deviation.

Previous studies used the PSS-14 to assess perceived stress in caregivers of individuals with various chronic illnesses, though these studies have been limited with respect to caregivers of individuals with multiple congenital anomalies and neurodevelopmental disorders. Baseline stress scores in our cohort were higher than those reported for caregivers of individuals with Alzheimer's disease, ${ }^{22}$ but lower than those reported for caregivers of children with cerebral palsy ${ }^{23}$ and Prader-Willi syndrome. ${ }^{8}$ There are likely multiple factors that contribute to the variability of stress levels among caregivers of different disorders or even the same disorder. Hassall et al studied 46 mothers of children with intellectual impairment and their results supported their hypotheses that parenting stress was higher when behavioral difficulties of the child were more severe and when the mothers displayed a more external locus of control for parenting. ${ }^{24}$ In addition, there was evidence for lover levels of parenting stress when there was more social support and a better sense of parenting effectiveness and satisfaction. ${ }^{24}$ It is known that there is a range of behavioral phenotypes in individuals with RASopathies and hence there is likely to be a range of parental stress in the RASopathies based on the behavioral profile.

Studies postulated that parental sex may explain differences in adjustment to caregiving responsibilities for individuals with disabilities and rare disease. ${ }^{24}$ In one study, mothers reported higher levels of stress and a higher burden of caregiving responsibilities as compared with fathers. ${ }^{25}$ In our cohort, we did not identify a significant difference in baseline stress levels between mothers and fathers. Though stress scores did trend downward for the entire cohort 1month postconference, the decrease was only statistically significant among men $(p=0.004)$. It is possible that women, who tend to report a higher burden of caregiving responsibility, may not benefit as much from a stress reduction perspective because of other stressors associated with being a primary caregiver. Men, who historically tend not to identify as the primary caregiver, ${ }^{8}$ may experience more short-term benefit from attending the support conferences.

Numerous studies have utilized the CHIP instrument to evaluate coping behaviors of caregivers of children with chronic disease. ${ }^{8,11,26,27} \mathrm{~A}$ higher percentage of the maximum score for each subscale indicates a higher use of that coping mechanism. In previous studies of caregivers of individuals with other chronic illnesses including epilepsy, juvenile idiopathic arthritis, Prader-Willi syndrome, and various physical disabilities maximum percentage scores have ranged from 66 to $77 \%$ for the CHIP I, 45 to $74 \%$ for the CHIP II, and 61 to $69 \%$ for the CHIP III. ${ }^{8,11,26,27}$ When one compares the CHIP scores of the baseline cohort of individuals with RASopathies to these studies, coping mechanisms detailed in the CHIP I appear particularly lower at $62.1 \%$ of the maximum score, suggesting that topics at the conference focusing on additional methods to better utilize mechanisms such as maintaining family integration, cooperation, and developing an optimistic definition of the situation could be important.

We found that the use of CHIP III coping behaviors, which pertain to understanding the medical situation through communication with other parents and consultation with medical staff, decreased across the entire intervention cohort at 6 -month postconference. The decrease in the use of these coping mechanisms was notable for women $(p=0.001)$ and for individuals who had attended 0 to 1 conferences $(p=0.007)$. The etiology for the difference in the use of these coping mechanisms between men and women is not known. Though we did not assess it in our study, previous studies of caregivers of children with chronic illnesses have demonstrated that women tend to identify as primary caregivers much more often than men. ${ }^{8}$ These studies postulated that men, who generally do not identify as primary caregivers, may have been 
able to maintain interactions with other parents and medical staff postintervention, while women may not have been able to utilize such coping mechanisms.

There are some limitations to this study. CFC syndrome and Costello syndrome are both very rare disorders, and thus, the number of study participants was limited. Additionally, though all caregivers were invited to participate in the study, significantly more women than men participated, which may limit our ability to draw conclusions on the basis of sex. Finally, participants were recruited to complete the baseline survey both before the conferences and at the beginning of the conferences themselves. Caregivers may have responded differently about their baseline stress and coping behaviors during the conferences than they would have if they had completed the survey before the conferences. Management and knowledge of the condition may change over time, and hence, other factors may impact changes in stress over time. $^{28}$

In summary, these data show that caregivers of individuals with CFC and Costello syndrome experience high levels of stress and support the concept that attending caregiver conferences provide coping resources in the short term to combat perceived stress. It is important to note that the content of various conferences is not always the same, but in general, the format of the conferences for the individuals with CFC and Costello syndrome included opportunities to connect with other families who are in similar circumstances and to speak with medical experts across various specialties. Given the rarity of these conditions, these resources are likely not always available to families after the conferences, as demonstrated by the underutilization of these coping mechanisms 6-month postconference. Given that compared with 1-month postconference, the PSS-14 stress scores did not significantly change from baseline to 6-month postconference, we hypothesize that increasing the frequency of conferences or developing other mechanisms to maintain support over time (e.g., virtual conferences, follow-up online forums, regional gatherings) will further help decrease stress in caregivers. Additional research to investigate the most effective alternative approaches to support families and augment conference formats will be important.

\section{Conflict of Interest}

None declared.

\section{Acknowledgments}

We would like to acknowledge CFC International and the Costello Syndrome Family Network for facilitating this work. We would also like to thank Jennafer Dotson for her work in study coordination and data processing. The research presented in the article was conducted while the first author was in training or to fulfill a degree requirement of the first author.

\section{References}

1 Tajan M, Paccoud R, Branka S, Edouard T, Yart A. The RASopathy family: consequences of germline activation of the RAS/MAPK pathway. Endocr Rev 2018;39(05):676-700
2 Alfieri P, Piccini G, Caciolo C, et al. Behavioral profile in RASopathies. Am J Med Genet A 2014;164A(04):934-942

3 Baker BL, Blacher J, Olsson MB. Preschool children with and without developmental delay: behaviour problems, parents' optimism and well-being. J Intellect Disabil Res 2005;49(Pt 8):575-590

4 Singer GH. Meta-analysis of comparative studies of depression in mothers of children with and without developmental disabilities. Am J Ment Retard 2006;111(03):155-169

5 Estes A, Munson J, Dawson G, Koehler E, Zhou XH, Abbott R. Parenting stress and psychological functioning among mothers of preschool children with autism and developmental delay. Autism 2009;13(04):375-387

6 Pierpont EI, Wolford M. Behavioral functioning in cardiofaciocutaneous syndrome: Risk factors and impact on parenting experience. Am J Med Genet A 2016;170(08):1974-1988

7 Neece CL. Mindfulness-based stress reduction for parents of young children with developmental delays: implications for parental mental health and child behavior problems. J Appl Res Intellect Disabil 2014;27(02):174-186

8 Tvrdik T, Mason D, Dent KM, et al. Stress and coping in parents of children with Prader-Willi syndrome: Assessment of the impact of a structured plan of care. Am J Med Genet A 2015;167A(05): 974-982

9 Cohen S, Kamarck T, Mermelstein R. A global measure of perceived stress. J Health Soc Behav 1983;24(04):385-396

10 Cohen S, Williamson G. Perceived stress in a probability sample of the United States. In: Spacapan S, Oskamp S, eds. The Social Psychology of Health. Newbury Park, CA: Sage; 1988

11 McCubin I, McCubin M, Patterson J, Cauble A, Wilson L, Warwick W. CHIP-Coping Health Inventory for Parents: an assessment of parental coping patterns in the care of the chronically ill child. J Marriage Fam 1983;45:359-370

12 Adviento B, Corbin IL, Widjaja F, et al. Autism traits in the RASopathies. J Med Genet 2014;51(01):10-20

13 Garg S, Brooks A, Burns A, et al. Autism spectrum disorder and other neurobehavioural comorbidities in rare disorders of the Ras/MAPK pathway. Dev Med Child Neurol 2017;59(05): 544-549

14 Bizaoui V, Gage J, Brar R, Rauen KA, Weiss LA. RASopathies are associated with a distinct personality profile. Am J Med Genet B Neuropsychiatr Genet 2018;177(04):434-446

15 Galéra C, Delrue MA, Goizet C, et al. Behavioral and temperamental features of children with Costello syndrome. Am J Med Genet A 2006;140(09):968-974

16 Axelrad ME, Schwartz DD, Katzenstein JM, Hopkins E, Gripp KW. Neurocognitive, adaptive, and behavioral functioning of individuals with Costello syndrome: a review. Am J Med Genet C Semin Med Genet 2011;157C(02):115-122

17 Bouma R, Schweitzer R. The impact of chronic childhood illness on family stress: a comparison between autism and cystic fibrosis. J Clin Psychol 1990;46(06):722-730

18 Randall P, Parker J. Supporting the Families of Children with Autism. Chichester: Wiley; 1999

19 McKinney B, Peterson RA. Predictors of stress in parents of developmentally disabled children. J Pediatr Psychol 1987;12 (01):133-150

20 Weiss MJ. Hardiness and social support as predictors of stress in mothers of typical children, children with autism, and children with mental retardation. Autism 2002;6(01):115-130

21 Sakkalou E, Sakki H, O'reilly MA, Salt AT, Dale NJ. Parenting stress, anxiety, and depression in mothers with visually impaired infants: a cross-sectional and longitudinal cohort analysis. Dev Med Child Neurol 2018;60(03):290-298

22 Cristancho-Lacroix V, Wrobel J, Cantegreil-Kallen I, Dub T, Rouquette A, Rigaud AS. A web-based psychoeducational program for informal caregivers of patients with Alzheimer's 
disease: a pilot randomized controlled trial. J Med Internet Res 2015;17(05):e117

23 Thanou E, Tsiou C, Kattami C, Chrousos GP, Darviri C. A stress management and health promotion intervention for parents of children with cerebral palsy and motor disability at the Infant Department of the Greek Center for the Protection and Rehabilitation of the Disabled (ELEPAP). Quasi-experimental study. Psychology (Irvine) 2016;7:557-564

24 Hassall R, Rose J, McDonald J. Parenting stress in mothers of children with an intellectual disability: the effects of parental cognitions in relation to child characteristics and family support. J Intellect Disabil Res 2005;49(Pt 6):405-418
25 Dellve L, Samuelsson L, Tallborn A, Fasth A, Hallberg LR. Stress and well-being among parents of children with rare diseases: a prospective intervention study. J Adv Nurs 2006;53(04): 392-402

26 Hobdell EF, Grant ML, Valencia I, et al. Chronic sorrow and coping in families of children with epilepsy. J Neurosci Nurs 2007;39(02):76-82

27 Cavallo S, Feldman DE, Swaine B, Meshefedjian G, Malleson PN, Duffy CM. Is parental coping associated with quality of life in juvenile idiopathic arthritis? Pediatr Rheumatol Online J 2009; 7:7

28 Gripp KW, Morse LA, Axelrad M, et al. Costello syndrome: clinical phenotype, genotype, and management guidelines. Am J Med Genet A 2019;179(09):1725-1744 